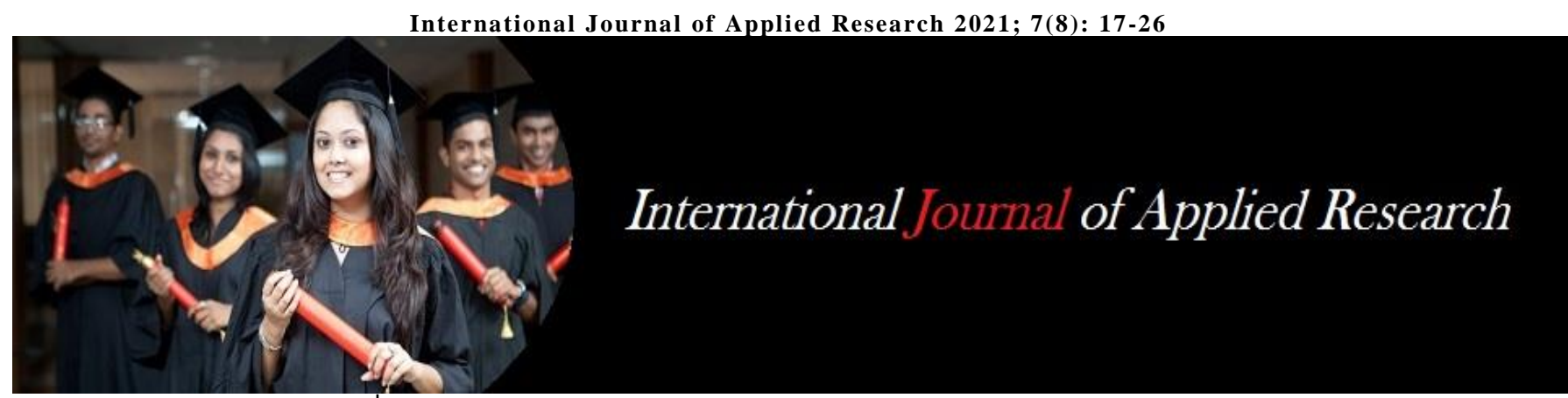

ISSN Print: $2394-7500$

ISSN Online: 2394-5869

Impact Factor: 8.4

IJAR 2021; 7(8): 17-26

www.allresearchjournal.com

Received: 24-05-2021

Accepted: 14-07-2021

Dr. Ranju Joshi Pandey

Department of Geography \&

NRM, Uttarakhand Open

University, Uttarakhand,

India
Corresponding Author: Dr. Ranju Joshi Pandey Department of Geography \& NRM, Uttarakhand Open University, Uttarakhand, India

\section{Migration of population: A major disaster of Uttarakhand}

\author{
Dr. Ranju Joshi Pandey
}

DOI: https://doi.org/10.22271/allresearch.2021.v7.i8a.8817

\begin{abstract}
Migration from Uttarakhand has been a major issue of discussion amongst the scholars and is being focused in social media since last few years. The original habitant migrated from their native place particularly in rural areas either to urban areas of the districts of Uttarakhand and also to other states for various reasons. The population enumerations data of Census 2011 was released in early 2012 shows that thousands of villages in various districts of Uttarakhand were found un-inhabited means reported zero population. Scholars paid their attention at that point of time also with assistance of additional categories of data but another important facet of study of migration could not be correlated at that point of time due to non availability of data on migration. Now the long awaited data on migration of Census-2011 has been released by the Office of the Registrar General India it will be appropriate to analyze the same particularly with reference to migration from Uttarakhand to other states for various age group with reasons of migration and also at this juncture when the country is facing major disaster of COVID-19 when people particularly village dwellers intends to come back to their native place. The study aims at to describe the factors responsible for migration, its causes and consequences in Uttarakhand on the basis of data on migration of Census, 2011.
\end{abstract}

Keywords: Migration, census, demographic, migrants, pull factor, push factor

\section{Introduction}

General Concept of Migration: One important facet of study on population is the study of migration arising out of various social, cultural, economic or political reasons. For a large country like India, the complexity of movement of population in different parts of the country helps in understanding the dynamics of the society. Migration process has been considered one of most important aspect of human life since very beginning. Nomadic tribes' always used to move from one place to another on wheels and temporarily settle at any open place with their family and bullock cart to perform their economic activity. Similarly labour engaged in construction activities and agriculture labour also migrate during harvesting season comprise seasonal migration. In early past peoples also used to move from move from one region to another in search of fertile land for developing cultivation. The reasons and motive of movement changes considerably over a period of time according to the development of society, changing social environment, needs to earn livelihood and also changing environment and geographical conditions. But in recent past the pace of migration changed rapidly when people started to migrate from rural areas to urban areas of other districts and cities and overseas basically in search of better employment, better educational and medical facilities. In modern world the study of migration has become important in the context of national planning also thus the analysis of migration data has gained much momentum in the modern era.

\section{Concept of Migration as adopted in Census}

A person is considered as migrant by place of birth if the place in which he is enumerated during the census is other than his place of birth. As a person could have migrated a number of times during his/her lifetime, migration by place of birth would not give a correct picture of the migration taking place currently. A person, on the other hand, is considered as migrant by place of last residence, if the place in which he is enumerated during the census is other than his place of immediate last residence which would give a better picture of current migration scenario. Census provides migration data on following categories of migration streams:- 


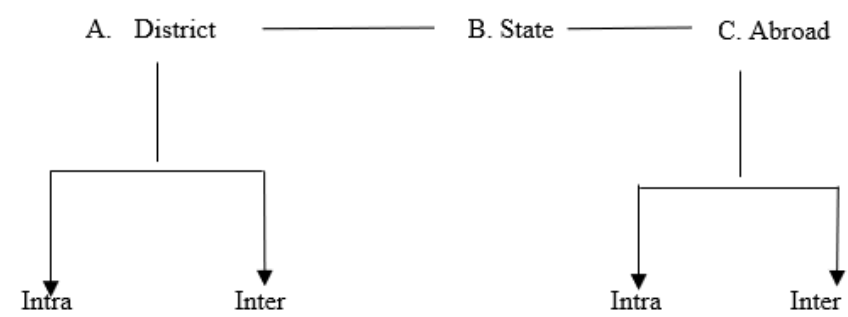

The data is captures further for each stream from rural to rural, rural to urban, urban to rural and abroad. Another important factor to study the migration is reason for migration for which people migrate from one place to another. Census collect data on following 7 reasons responsible for migration:-

\begin{tabular}{|c|c|}
\hline 1 & Work/employment \\
\hline 2 & Business \\
\hline 3 & Education \\
\hline 4 & Marriage \\
\hline 5 & Moved after birth \\
\hline 6 & Moved with household \\
\hline 7 & Others \\
\hline
\end{tabular}

Though questionnaire canvassed during census the data is collected for Rural / Urban Status, duration of residence at place of enumeration and reasons for migration but the data is presented by cross classification with other parameters like age group and educational qualifications. Census is collecting data on migration since census of 1981. In 1881's Census, a question on place of birth was introduced for the first which continued till 1951. In 1961 its scope was widened by gathering information on rural and urban status of birth place and duration of residence in the place of enumeration which was different from place of birth. In Census of 1971 for getting better information an additional question on place of last residence was introduced and in 1981 the scope was further widened by introducing another important parameter of reason for migration but this question was canvassed on sample basis rather than universal basis. Since 1991 the question on migration has continued to be canvassed on universal basis without any further modification.

\section{Why people migrate and its factor}

Migration is a global phenomenon caused not only by economic factors but many other factors like social, political, cultural, environmental, health, education. Employment, better educational facility are the factors which attract mostly males to migrate in urban area of other district or to other States. In urban areas diversification of economy and urbanization provides a lot of job opportunities. The female usually migrates as accompanists of males through several other factors like after marriage or with the family when male migrate due to other factors. From rural areas people migrate due to small land holding resulting in less income which is not sufficient to lead a comfortable life as people have desire to maintain a good standard of living and also to provide better education to their children. To some extent non availability of better medical facility also attract people to migrate to urban areas of district headquarters, municipal towns or to other states. Push and pull are the two factors responsible for out and in migration.
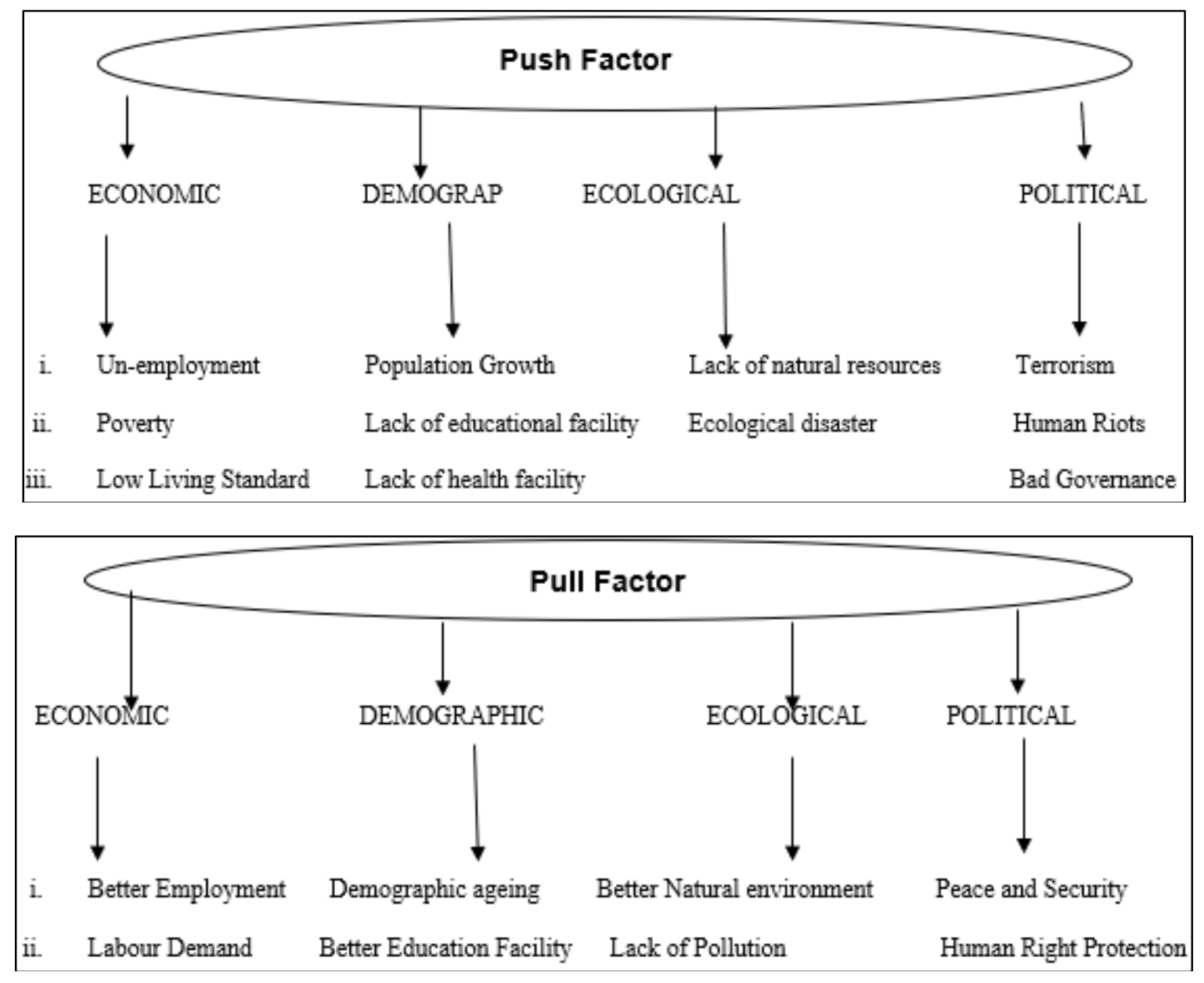


\section{Trend of Migration at National Level}

The Office of the Registrar General India is responsible for conducting decadal census through its Directorate of Census in States / Union Territories. Though data on migration of last decadal census of 2011 has been released by the RGI through its D series tables in recent past General trend of interstate migration in India from one stream to another stream between census 2001 and 2011 i.e. for 9 years is depicted with the help of following line graph;

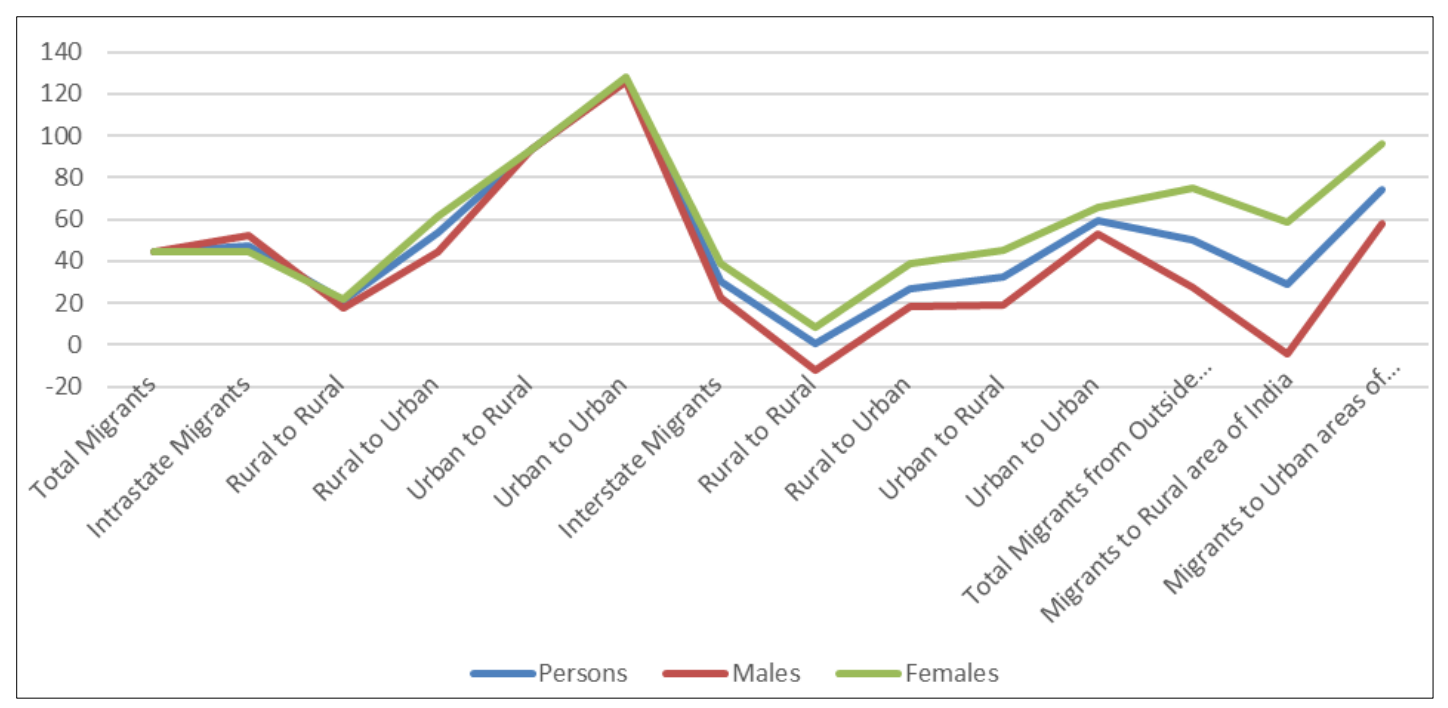

Graph 1: Decadal Growth of stream wise Inter State Migrants by place of last residence India, 2001-2011

In case of Interstate Migration decadal growth of male migrant who migrated from rural to urban areas of other state is recorded 18.5 whereas corresponding growth of migrant male who migrated from urban areas to rural areas is recorded 19.0. In case of female the growth of migrant from rural to urban is recorded 39.0 percent and 45.5 percent from urban to rural. As such the proportion of migrants from urban areas to rural areas for males and females is on higher side. Why people settled in rural areas of other State after migrating from urban areas? This can perhaps to be attributed to the facts that due to cheap land prices and rent people preferred to settle in rural areas of other states after migrating from urban areas. During the decade of 2001-2011the growth of migrant from urban to urban is recorded 52.9 for males and 65.5 percent for females. This indicates that people have started to live in urban areas leaving their villages deserted.

The bar graph given below gives a glimpse of migration of people within the State of their enumeration or Intrastate from one stream to another stream:

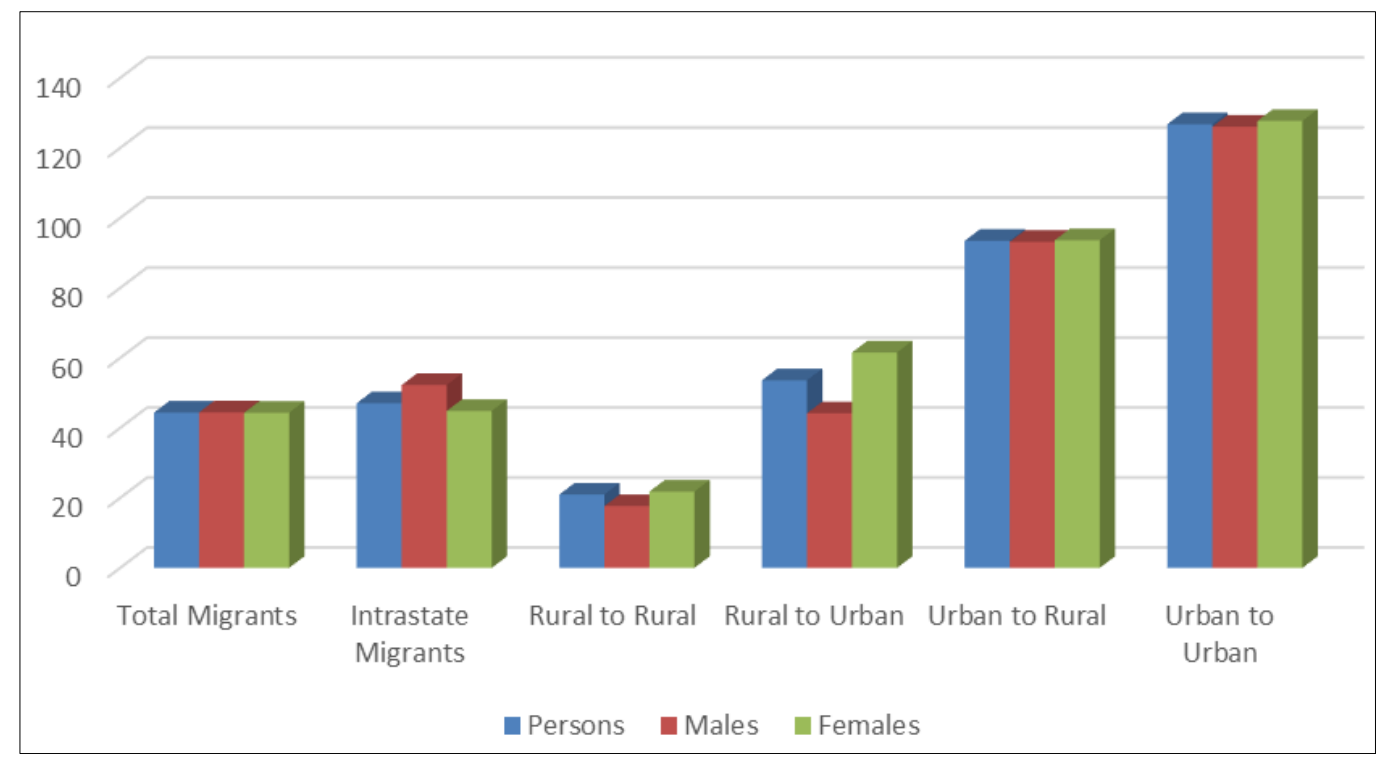

Graph 2: Decadal Growth of stream wise Intra State Migrants by place of last residence India -2001=2011)

The above graph also depicts the same pattern as for Interstate. Within the State also the patter of migration shows that much people are settling in urban areas as compared to rural when they migrated within their own state of enumeration. During the decade 2001-2011 the growth of male and female migrants from Rural to Urban is recorded
44.1 and 61.5 respectively. Like Interstate migration in intrastate migration more people settled in rural areas after migrating from urban areas. This may be due to the fact that either they migrated to other district of their state due to education, employment or for any other reason or migrated for better facility in the place where they migrated and 
prefer to settle in rural areas due to lower land price and rent. However this can be ascertain with cross analysis of data with reasons of migration.

\section{Demographic profile of migration in Uttarakhand In migration}

Though out migration of original habitat of Uttarakhand to other States is a major disaster but at the same time people from other States are also migrating to Uttarakhand for various reasons. This in migration on one hand though contributing in population growth of Urban Areas of some the districts but at the same time it has alter demographic profiles of communities, as most of the young men move out, leaving behind only the women and elderly.

The following 3 bar diagrams gives a glimpse of 10 top most States from where people migrated to Uttarakhand for Work/Employment, marriage and education respectively:-

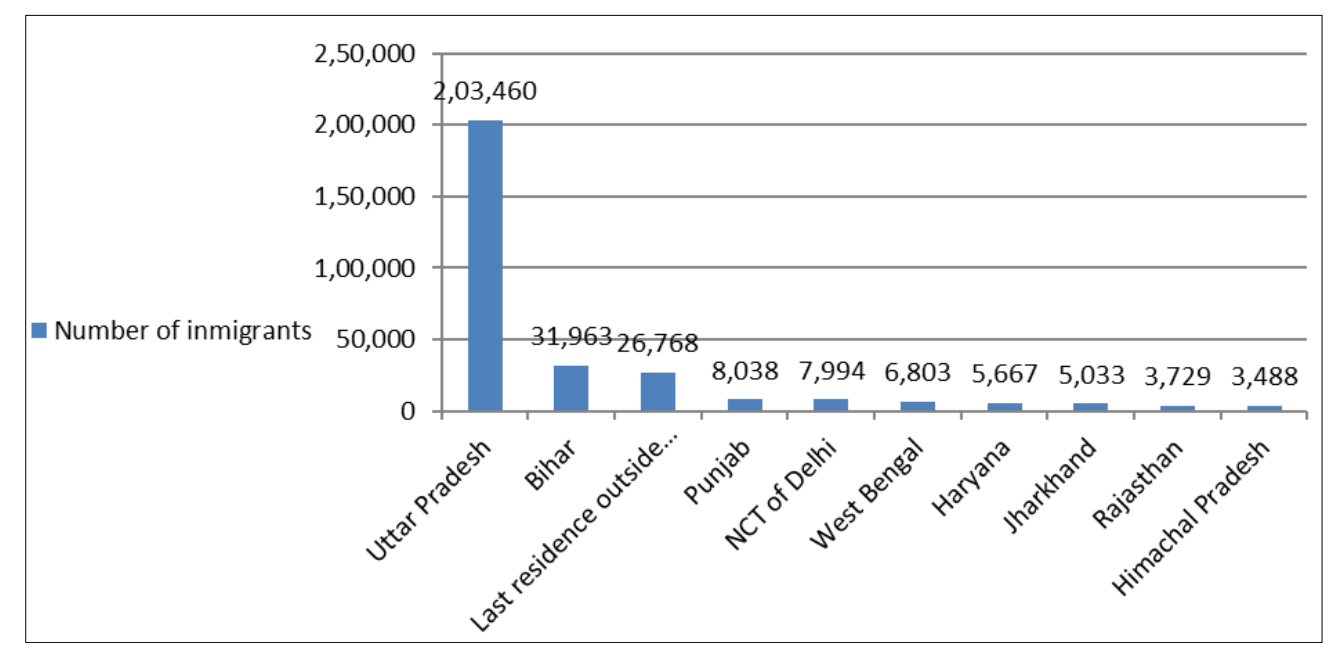

Graph 3: Top 10 States from people migrated to Uttarakhand due to Work/Employment -2011

The data reveals that for out of 10 top States from where people migrated to Uttarakhand for work and employment 5 States lies in Northern Zone, 3 in Eastern Zone and 1 in Western Zone. 12,822 people also migrated to Uttarakhand from outside the Country. The number of migrants from Uttar Pradesh is on higher side is due to the fact because
Uttarakhand has been created by delimitation of Uttar Pradesh. Bihar is another State from where more than 31,000 persons migrated to Uttarakhand for work and employment who are mostly engaged in construction and agriculture sector.

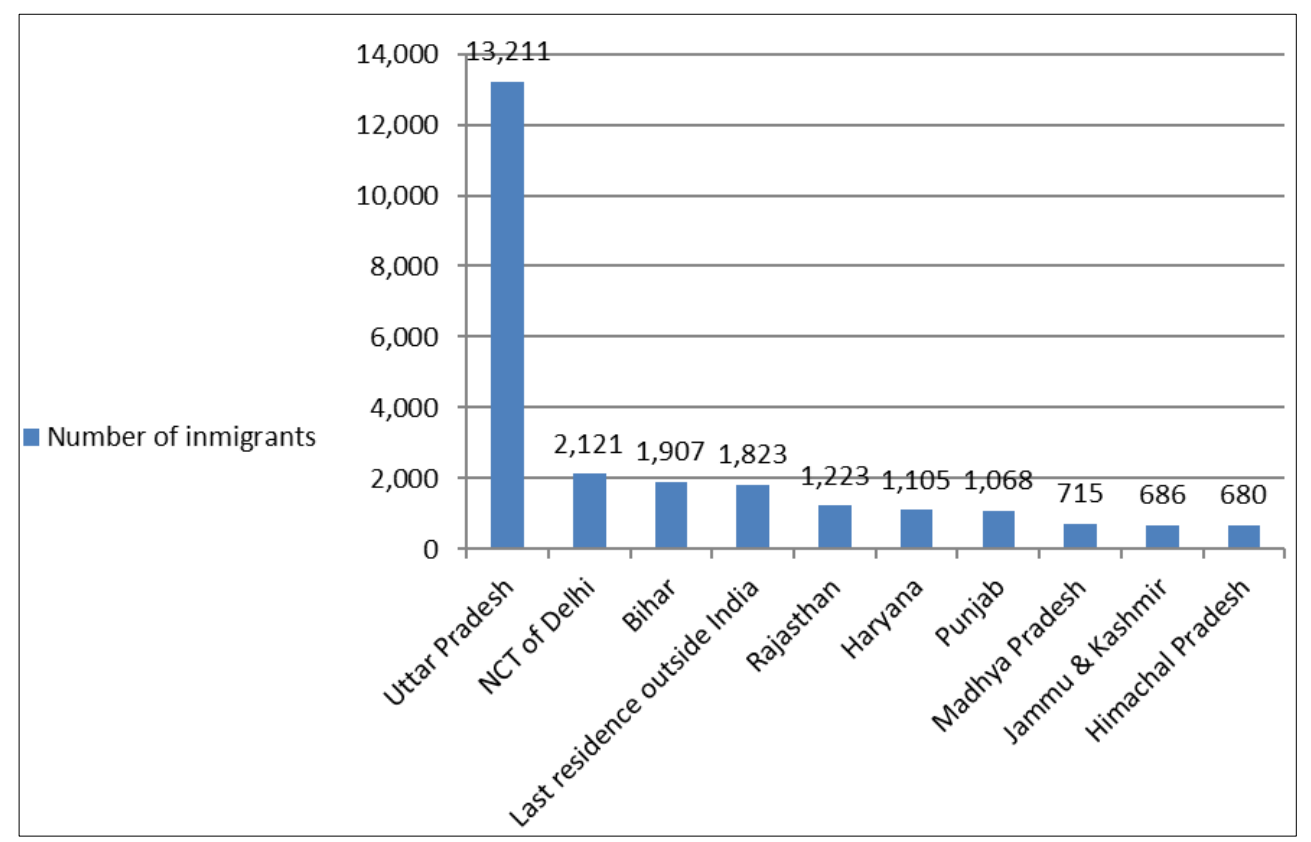

Graph 4: Top 10 States from where people migrated to Uttarakhand for Education-2011

On similar pattern most of immigrants of Uttarakhand migrated due to education are from Northern Zone comprising 6 States. The number of States from people migrated to Uttarakhand for education from Eastern, Western and Central Zone is 1 in each category. Even from Delhi 2121 people migrated due to education due to fact that it is comparatively rather difficult to get admission in higher studies. 1823 people also migrated from outside India to Uttarakhand for education out of which 1548 were from Asian countries perhaps due to the better education facility in India as compared to their countries. 


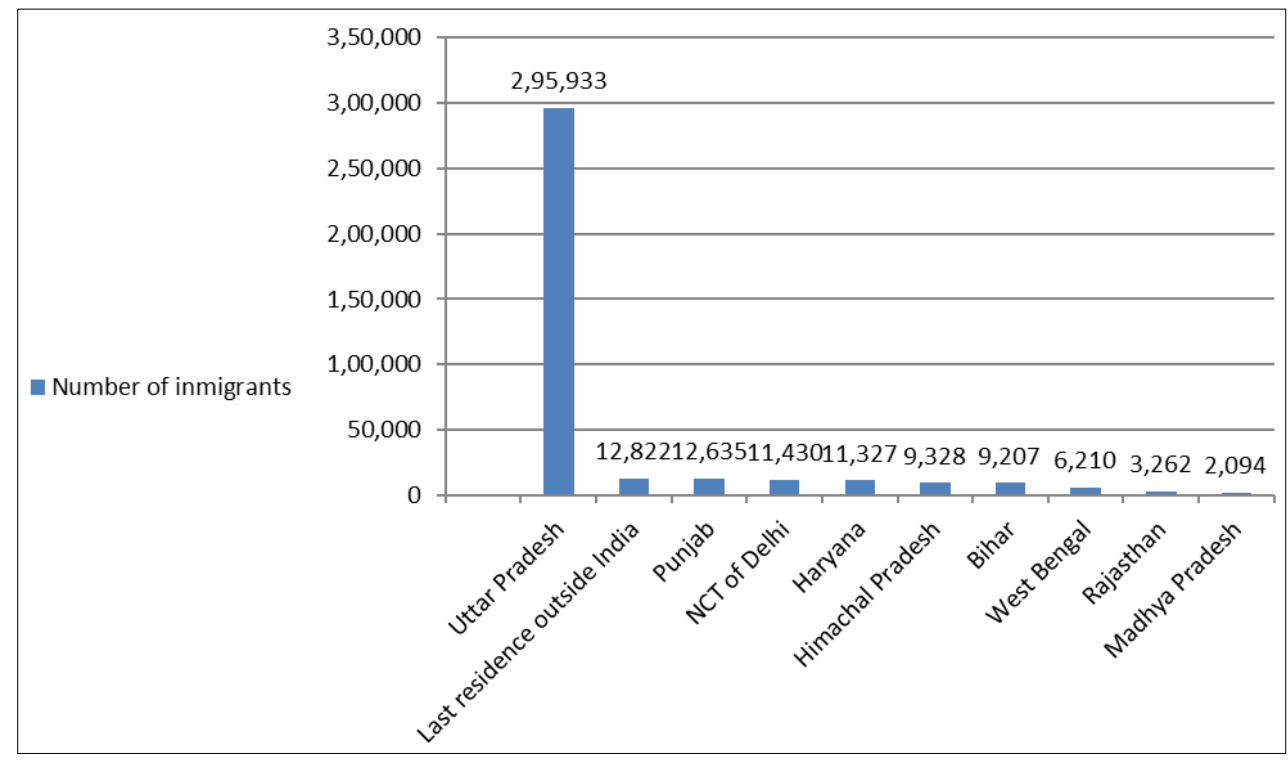

Graph 5: Top 10 States from where people migrated to Uttarakhand due to marriage -2011

The above data depicts that people have migrated to Uttarakhand from outside India for marriage also. Out of total 12, 822 who migrated for marriage 10,572 are from Asian Countries. The top 5 States, from which people migrated to Uttarakhand for marriage, lies in Northern Zone which establish good social relation with these States and also cultural resemblance up to some extent. People of Uttarakhand do have good social relation with Bihar and West Bengal also as 9,207 and 6,210 people respectively reported marriage as reason of their migration to Uttarakhand.

\section{Out Migration}

As presented above from the general trend of migration from rural to urban and urban to rural it has been established that pace of migration from rural to urban is on higher side and people are migrating from rural to urban areas leaving their villages deserted. Since the objective of the paper is to focus on migration basically out migration from Uttarakhand in the following paragraphs attempts has been made to present the scenario of the out migrants on the basis of migration data released by Office of the Registrar General of India (RGI).

\section{Out migration pattern on the basis of Population Enumeration basic data}

The Primary Census Abstract of 2011 was released by RGI long back. RGI has also released District Census Handbook for each district of the country which contains non- census data also which is cross classified by the population census data. Village Directory is an important component of each District Census Handbook which contains the data on population with other basic amenities like health, education, drinking water facility, electricity etc. As per village directory and Primary Census Abstract of all the Districts of Uttarakhand in 2011 total 1048 villages found un-inhabited means with recording zero $(0)$ population:-

Table 1: Number of Villages in the Districts of Uttarakhand reported 0-1 household - 2011

\begin{tabular}{|c|c|c|c|c|c|c|}
\hline $\begin{array}{l}\text { Sl. } \\
\text { No. }\end{array}$ & Name of District & $\begin{array}{c}\text { Total } \\
\text { Village }\end{array}$ & $\begin{array}{c}\text { Number of villages } \\
\text { reported o (zero) } \\
\text { household i.e Un-inhabited }\end{array}$ & $\begin{array}{c}\text { Number of } \\
\text { villages reported } \\
\text { only } 1 \text { household } \\
\end{array}$ & 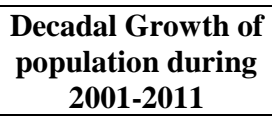 & $\begin{array}{r}\text { Sex } \\
\text { Ratio - } \\
\mathbf{2 0 1 1} \\
\end{array}$ \\
\hline & \multicolumn{6}{|c|}{ Kumaon Region } \\
\hline 1 & Almora & 2289 & 105 & 22 & -1.3 & 1139 \\
\hline 2 & Champawat & 717 & 55 & 16 & 15.6 & 980 \\
\hline 3 & Bageshwar & 947 & 73 & 15 & 4.2 & 1090 \\
\hline 4 & Nainital & 1141 & 44 & 9 & 25.1 & 934 \\
\hline 5 & Pithoragarh & 1675 & 103 & 26 & 4.6 & 1020 \\
\hline \multirow[t]{3}{*}{6} & Udamsingh Nagar & 688 & 14 & 1 & 33.4 & 920 \\
\hline & Total & 7457 & 394 & 89 & & \\
\hline & \multicolumn{6}{|c|}{ Garhwal Region } \\
\hline 7 & Rudra Prayag & 688 & 35 & 10 & 6.5 & 1114 \\
\hline 8 & Uttar Kashi & 707 & 13 & 6 & 11.9 & 958 \\
\hline 9 & Haridwar & 612 & 94 & 13 & 30.6 & 880 \\
\hline 10 & Dehradoon & 748 & 17 & 2 & 32.3 & 902 \\
\hline 11 & Tehri & 1862 & 88 & 14 & 2.3 & 1077 \\
\hline 12 & Chamoli & 1246 & 76 & 16 & 5.7 & 1019 \\
\hline \multirow[t]{3}{*}{13} & Garhwal & 3473 & 331 & 59 & -1.4 & 1103 \\
\hline & Tot al & 9336 & 654 & 120 & & \\
\hline & Grand Total & 16793 & 1048 & 209 & & \\
\hline
\end{tabular}

The data of population enumeration indicates the magnitude of out migration particularly from villages. Out of total 16 ,
793 villages of Uttarakhand 1048 villages were recorded deserted, so called be-chirag, with 0 household residing. 
Though 209 villages habitation was recorded but with only 1 household residing means to say with a population of 5 to 6 persons in such villages. On comparing the scenario of Kumaon and Garhwal region it is observed the problem of migration is more alarming in Garhwal region. Apart from deserted villages the population has declined during the decade of 2001-2011 in Almora and Garhwal indicating the magnitude of out migration. The population has grown considerably in Districts Nainital, Udham Singh Nagar of Kumaon region basically due to the reason people from remote hills are settling in these districts due to fertile land of tarai and setting up of Industries. In Garhwal region population during decade 2001-2011 grown considerably in Dehradoon due to the Capital City of Uttarakhand and in Hardwar due to the reason of being holy city of Uttarakhand and gate way of entire Garhwal reason. The sex ratio of Uttarakhand which is in favour of female almost in all the districts is due to the fact that mostly male migrated unaccompanied with their spouse.

Zone wise distribution of out migration: The following doughnut gives a picture of out migrants from Uttarakhand to different geographical zones of India as per Census 2011.

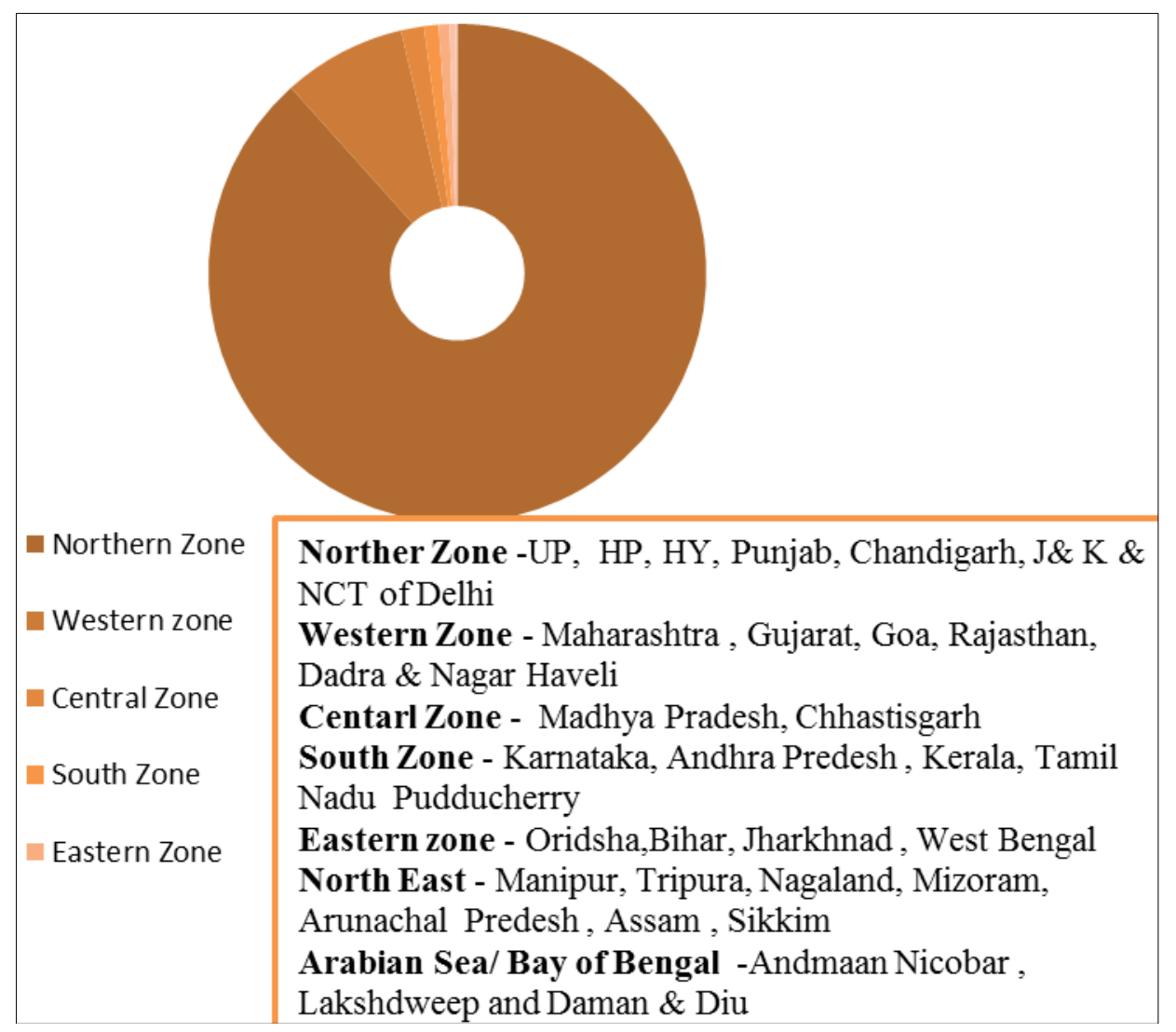

Fig 1: Percentage of out Migrants to different zones-2011

Zone wise distribution of Stats/ UT reveals out of 34 States / UTs (excluding Uttarakhand), prevailing at the time of 2011 Census 8 States/UTs are in North East zone followed by Northern Zone in which 7 States lies. The Western and Sothern zone each comprise of 5 States. East zone consists of 4 States whereas Central zone consists of only 2 States. The Andaman \& Nicobar, Daman \& Diu and Lakshadweep lies in Bay of Bengal / Arabian Sea. Out of total out migrants of Uttarakhand 88.36 percent migrated to the States lies in Northern Zone and 8 percent migrated to the
States of Western zone. In the States of Central zone only 1.49 percent persons migrated from Uttarakhand. In rest of zones the proportion of migrants recorded less than 1 percent as per Census -2011.

\section{Sex wise distribution of out migrants}

With the help of following bar diagrams attempts has been made to give a glimpse of out migrants to top 10 States for males and females separately. 


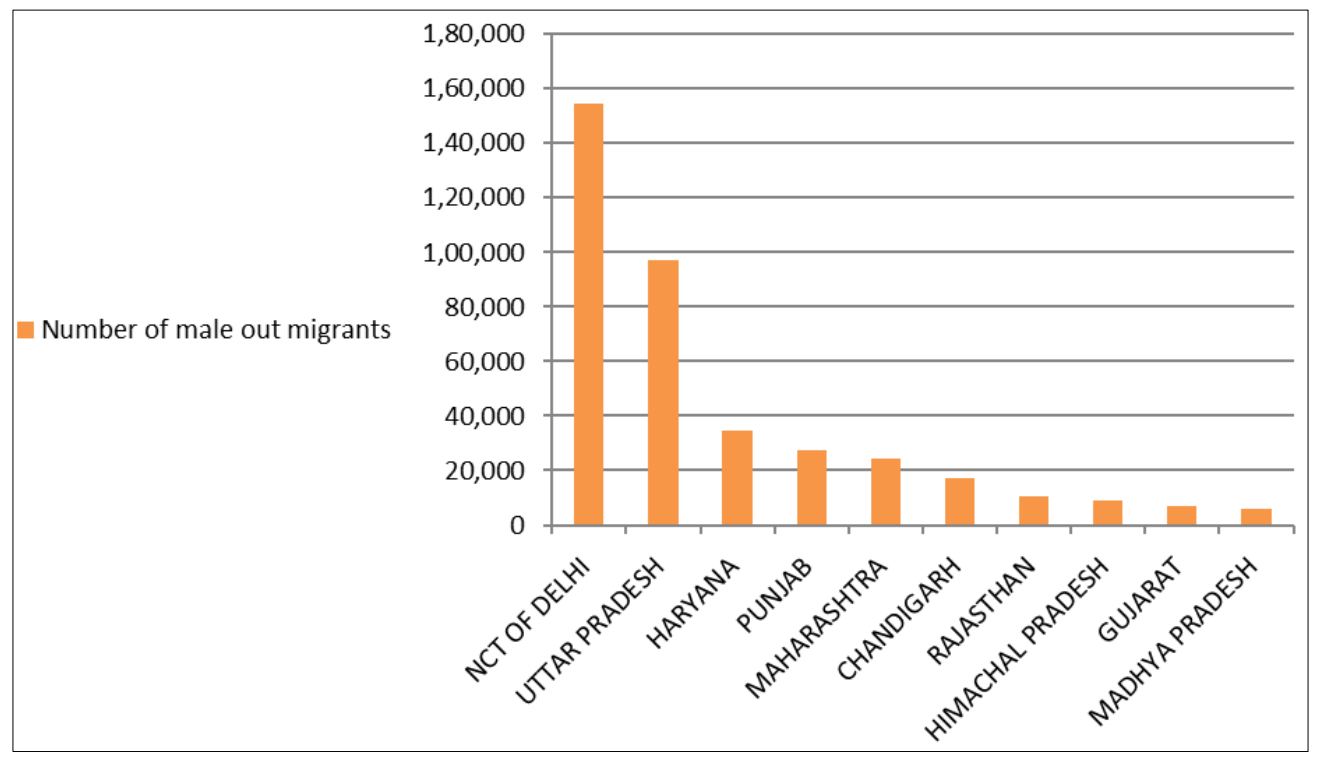

Graph 6: Number of male out migrants to top 10 States -2011

- Number of Female Out Migrants

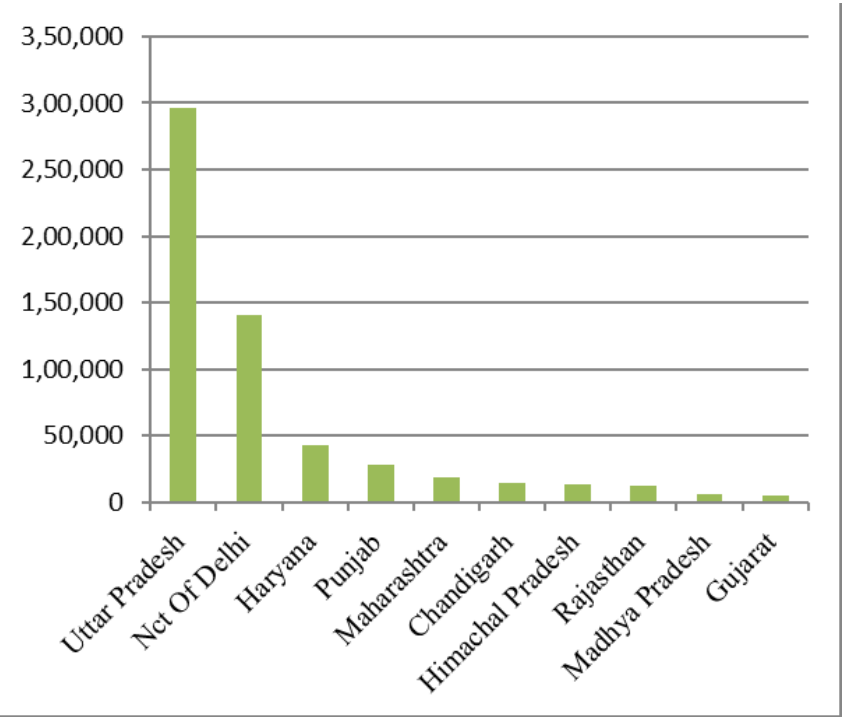

Graph 7: Number of Female out Migrants to top 10 States-2011

The top States to which Males and Females both migrated are NCT of Delhi, Uttar Pradesh, Haryana, Punjab, Maharashtra, Chandigarh, Rajasthan, Himachal Pradesh, Gujarat and Madhya Pradesh. Though the States are same but if we look number of migrants rank wise the picture differs slightly. In case of males the highest number of Males migrated to NCT of Delhi followed by UP but in case of female Uttar Pradesh is at first rung of the ladder. In case of female NCT of Delhi occupied second position. To other States also considerable numbers of males and females migrated. Delhi Occupied the top position as males migrated due to work and employment and in case of female Uttar Pradesh occupied top position as most of the females have migrated due to the reason of marriage but to ascertain this cross classification of data with reason of migration will be of paramount importance.

\section{Reasons of Out Migration}

i. The collect data for reasons of migration on following parameter:

ii. Work/ Employment iii. Education

iv. Marriage

v. Business

vi. Moved after Birth

vii. Moved with Household

viii. Others

As per general trends the majority of males migrate for work/employment, education and business whereas in case of females the primary reasons of migration are marriage, moved after birth and moved with households. With the help of following bar diagrams an attempt has been made to present magnitude of out migrants for 10 top states for males and females due to the reasons of work/employment, education and marriage. The percentage of out migrants for both the sexes has been commuted taking total migrants to other States with in India (Persons - 9, 93,570, Males - 4, 02,429, Females - 5, 91,149). The top 10 States has been arranged in order of proportion of male migrants.

\section{Out Migrants for work/employment}




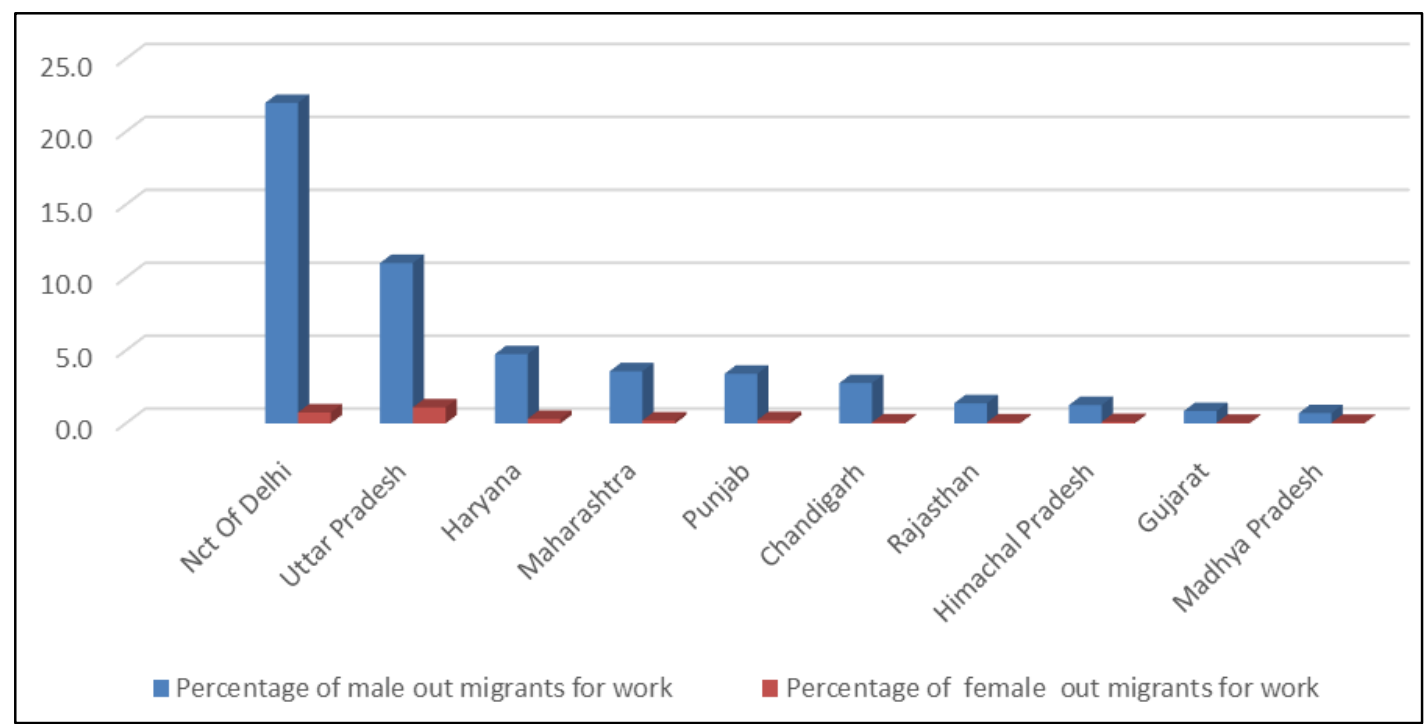

Graph 7: Top 10 States to which Males and Females Migrated to other States for Work-2011 (Top states are in order of male migrants)

The data depicts that out of total males who migrated due to work /employment 22.0 percent migrated to NCT of Delhi and 11.0 percent migrated to Uttar Pradesh. In case of other 8 states amongst top 10 the magnitude of out migration for work and employment is recorded in the range of $4.8 \%$ (Haryana) to $0.7 \%$ (Madhya Pradesh. In case of female most of the females who out migrated for work/ employment migrated to Uttar Pradesh $(1.10 \%)$ followed by NCT of Delhi $(0.75 \%)$. Of the remaining 8 States in case of females the proportion ranges between 0.31 (Haryana) to 0.04 (Madhya Pradesh). Over all it is seen for work and employment mostly out migration took place to the states lies in Northern and Western Zone. People do have migrated to other States/UTs also for work and employment but in small numbers.

\section{Out migration for Education}

Magnitude of migration for education is not very high as total 14,707 persons out migrated from Uttarakhand within India for education out of which 9424 migrated to top 10 states. For education majority of males migrated to NCT of Delhi constituting 1.02 percent of total male out migrants followed by Uttar Pradesh (0.55 percent). 0.22 percent females migrated to NCT of Delhi and 0.21 percent migrated to Uttar Pradesh for education. Like males similar trends has been noticed as states of Northern and western India occupied top 10 place on the basis of proportion of out migration within India for education. A glimpse of above trend can be glanced through with the help of following graph.

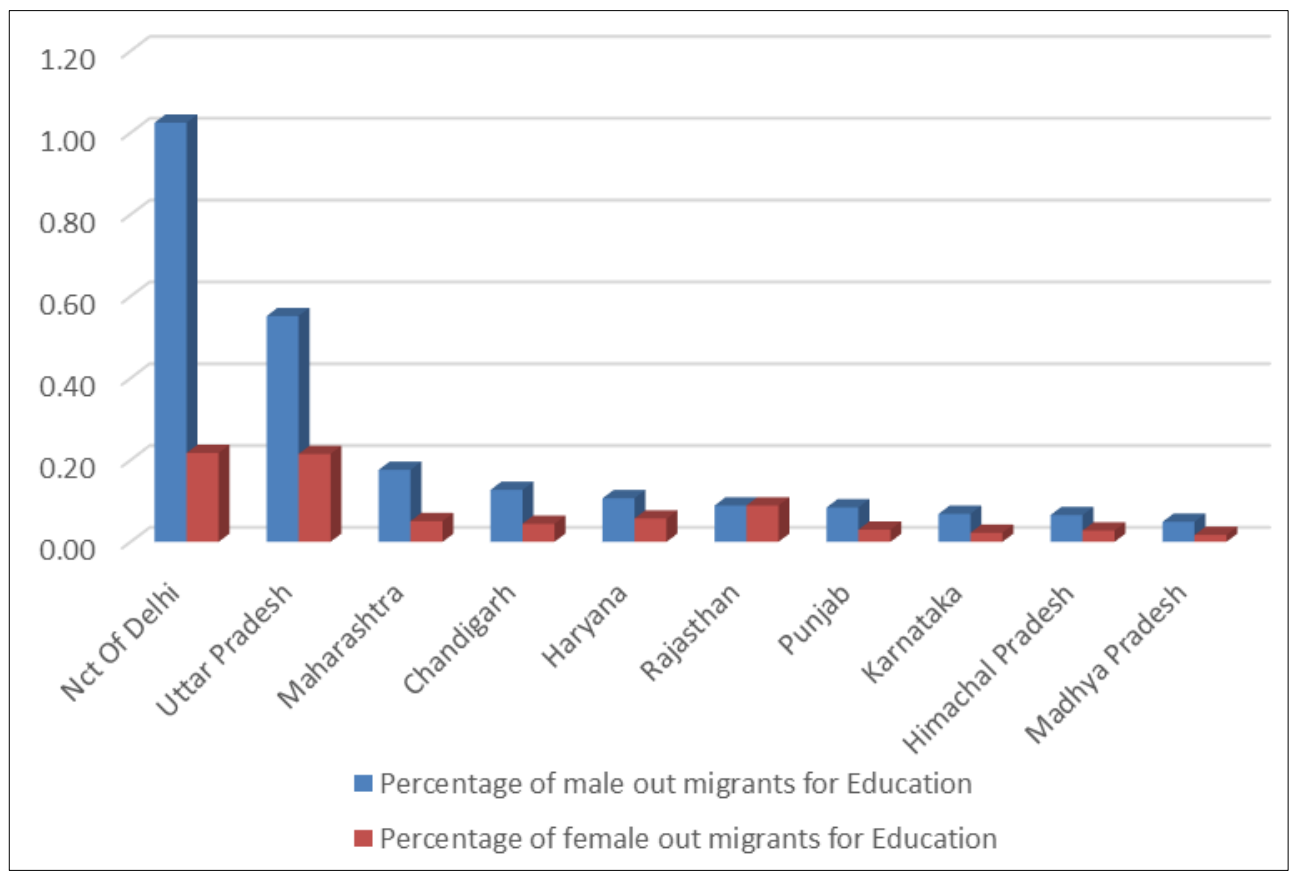

Graph 8: Top 10 States to which Males and Females Migrated to other States for Education-2011 (Top states are in order of male migrants)

\section{Out Migration due to marriage}

Marriage is another important factor due to which almost permanent migration took place. The following graphs give a comparative picture of female and male out migrants who migrated to other States of India due to the marriage; 


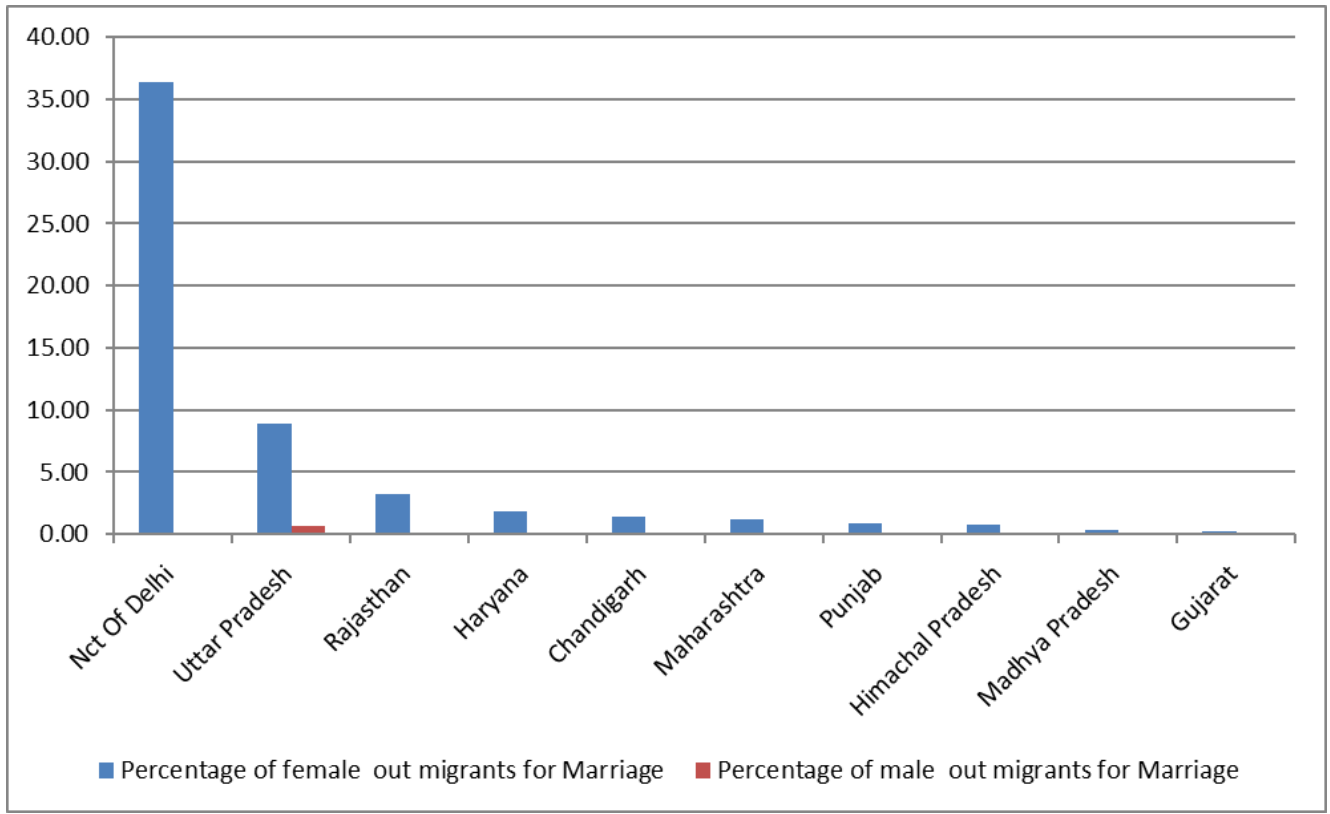

Graph 9: Shows in Percentage of famale out migrants for marriage and Percentage of male out migrants for marriage

The picture of this graph is different from other two graphs given above as the data depicts that magnitude of migration of female is much higher than males. Out of total 5.91 lakhs migrated females 3.34 lakhs females migrated due to the marriage. Out of these 3.34 lakhs female migrants majority of females comprising of 3.26 lakhs migrated to these top 10 States. 2.15 lakhs females migrated to NCT of Delhi alone and 0.52 lakhs to Uttar Pradesh due to marriage. In case of males migration due to marriage is almost negligible. Most of outmigration due to marriage is to the States of Northern zone indicating good social relation as already seen above in case of immigrants.

\section{Age Group wise out migration of males}

The line graph below gives an idea about age group wise number of out migrants during last 9 years means between census of 2001-2011. The data in the graph has been presented for three broader age group i.e. 10-39, 40-59 and $60+$. It is evident from the graph that between 2001-2011 majority of out migrants were youth who migrated to Uttar Pradesh, Haryana, Maharashtra, Himachal Pradesh \& Gujarat. Comparatively migration in the age group 40-59 is low and very low in age group 60+. This establish that majority of youth are migrating particularly for work and employment which appears to be major problem of Uttarakhand.

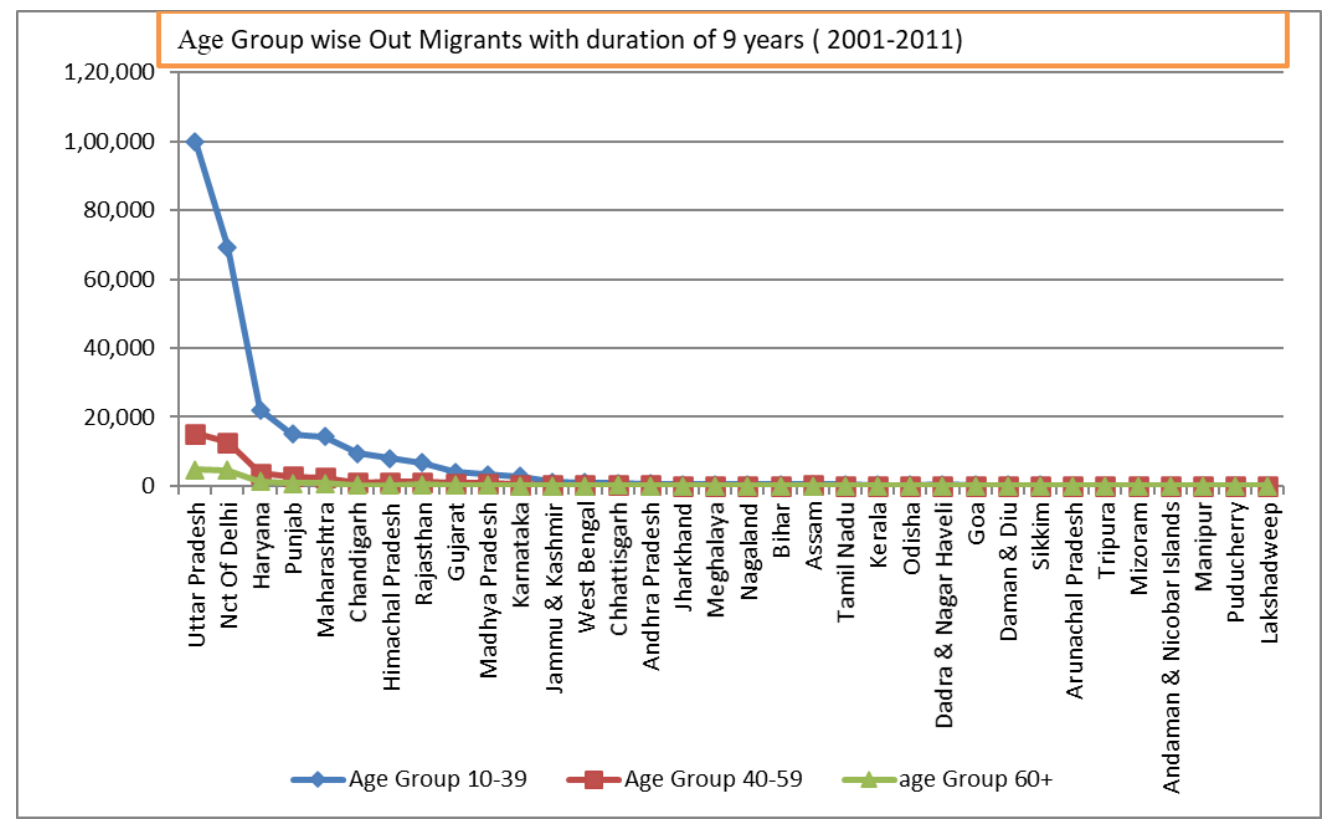

Graph 10: Pros and cons of migration

Migration fills the gaps between demand and supply of labour and also provides proper opportunity to skilled labour. Due to large scale migration particularly of labour class the labour is available comparatively at cheaper rate to small farmers and also in construction sector. Migration also helps in well being of migrants as they move from an area having inadequate employment, education facilities which improve their quality of life. The exchange of culture, knowledge, language improves social life of migrants and also of original inhabitants. Not only this when persons 
moves to new place for better employment and education it also helps in boosting the economy of their native place as they usually used to visit their native place.

Besides above positive aspects migration have negative effect for original and destination place both. The major negative point is that the original place suffers from loss of original inhabitant which adversely affects the culture of that area. Emigration in large numbers can alter demographic profiles of communities, as most of the young men move out as evident from age group wise graph of out migrants. Demographic profile of that place change drastically to people migrates in large number particularly in Capital cities and Metropolitan Cities. In the place to which people migrates in large number The proportion of old, children and females increases due to out- migration in source region.

\section{Conclusion}

As evident from the data presented by Census on migration lots of males and females are migrating from their native village to nearby urban area, to other district of the State and also to other States. The reasons of migration clearly indicate majority of males have migrated due to work and employment. Though other factors like education, family moved have also contributed to the number of male migrants but in small number as compared to those who migrated for work and employment. In case of female migrants the marriage has been recorded as a major factor. Obviously when male will move out for betterment definitely and will get married within their own culture their spouse will also move out contributing towards large number of female out migrants. The age group wise also reveals that majority of youth have out migrated, between 2001-2011, resulting in brain drain of youth from Uttarakhand. Needs has arisen now Government should focus on making a fool proof plans in different sector which will attract youth to stay in their native. Until and unless proper planning will not be formulated by focusing on the reasons of migration and non - availability of facilitates in the villages / towns from where people are migrating it will be difficult to check out migration and in the coming years more villages will be in the category of deserted.

\section{Covid 19 and return of migrants}

In the present scenario of COID-19 thousands of migrants returned to various districts of Uttarakhand. Most of them are those who left hilly area in search of employment. The migrants were engaged in various sectors like hospitality, transport, hotel/ restaurant industry, and some were highly skilled engaged in small private firms. They were forced to return to their home town after facing long term difficulty of their livelihood This is an opportunity for the Government to take appropriate steps to retain them by implementations of useful schemes and gainfully employing them.

\section{Suggestions}

In migration prone area improvement in financial and human resources sector will be of paramount importance. Development of proper strategies in backward areas having small land holding, low income, low living standard, less agricultural productivity will definitely help to check migration up to a reasonable extent. Providing employment facilities in rural areas will minimize the rural to urban migration and also to cities. All basic amenities like roads, electricity, safe drinking water, health facilities in rural areas are required to be improved considerably to prevent migration.

The Rural Development \& Migration Commission of Uttarakhand submitted its report in September, 2019. Though the commission has submitted its recommendations on various parameters but the following recommendations are reproduced:

a. Focus should be laid on works that lead to additional income for women folk.

b. Schemes should be planned for protection of the crops against monkeys.

c. Work under various scheme of water conservation like UDWDP, NRLM should be accelerated.

d. Efforts should be made to tap the real potential of medicinal and aromatic plants by transforming it into livelihood generation activity.

e. Supply chain of mushroom production to be strengthened which has been proved to be profitable.

f. Conversing Natural Resources facilities through convergence is needed to be introduced in scattered mountain region.

g. Direct chain should be established for hotels, resorts enabling them to buy from local areas by reducing cost of transportation.

h. Clear link between skill development and livelihood needs to be established

i. Integrated Training covering agricultural and animal husbandry related skill to be introduced to increase self -employment potential.

j. Avenues to be explored for traditional energy sources

$\mathrm{k}$. Efforts should be made to expand co-operative farming

1. In the field of dairy and fishery commercial production through capacity enhancement, access to nutrient rich fodder, creation of market place and proper branding requires to be increase.

By taking adequate steps as suggested by Rural Development \& Migration Commission and also other suggestions the migration from Uttarakhand can be controlled up to a reasonable extents which will definitely help in protecting the rich culture and habitat particularly of villages and life and prosperity in villages will revive.

\section{Acknowledgement}

I express my deep sense of gratitude to my respected and learned guide Professor R.K. Pandey, D.S.B. Campus Nainital, whose valuable help and guidance played a vital role in completion of this research paper. I also want to express my deepest thanks to my uncle, Shri G.C. Joshi, for the guidance, support and encouragement for this research paper. My sincere thank goes to my mother, my husband Sanjay Pandey for their motivational support to complete the research paper. Special thanks to Mr. Dwijesh Upadhyay and Chaitanya Pandey who support and gives valuable time for this research paper.

\section{References}

1. Data Source: Population enumeration and Migration data as Published by Office of the Registrar General, India.

2. Recommendations (a to i) - Report of Rural Development and Migration Commission. 